\title{
Not All Errors Are Alike: Theta and Alpha EEG Dynamics Relate to Differences in Error-Processing Dynamics
}

\author{
Joram van Driel, ${ }^{1}$ K. Richard Ridderinkhof, ${ }^{1,2}$ and Michael X Cohen ${ }^{1,3}$ \\ ${ }^{1}$ Department of Psychology, University of Amsterdam, 1018 XA, Amsterdam, The Netherlands, ${ }^{2}$ Cognitive Science Center Amsterdam, University of \\ Amsterdam, 1018 WS, Amsterdam, The Netherlands, and ${ }^{3}$ Department of Physiology, University of Arizona, Tucson, Arizona 85721
}

Performance errors in conflict tasks often result from inappropriate action impulses, and are thought to signal the need for increased control over the motor system. However, errors may also result from lapses in sustained attention, which may require different monitoring and adaptation mechanisms. Distinguishing between the mechanisms of adaptation is important as both error types may occur intermixed. To this end, we measured EEG of healthy human subjects while they performed three variants of the Simon task in which errors were more likely to occur due to attentional lapses, failures of motor control, or both. Behavioral results showed that subjects exhibited less conflict effects and less impulsive errors in sustained attention compared with the other Simon conditions. Time-frequency analyses of EEG data showed that the sustained attention Simon condition, compared with the motor control Simon condition, was characterized by: (1) less error-related MFC theta (4-8 Hz) power and an absence of error-related MFC-DLPFC theta phase synchronization; (2) stronger error-related suppression of parieto-occipital alpha (8-12 Hz) power and stronger parieto-occipital-frontal alpha synchronization. A control experiment, using SART (the Sustained Attention to Response Test), confirmed that adaptation after attentional lapses involved posterior alpha power suppression, in addition to inter-regional frontal theta activity. Together, these results suggest that at least two cortical mechanisms exist for performance monitoring, and that different tasks and task-settings can recruit these mechanisms in a different way. Post-error brain dynamics thus consist of heterogeneous activity from multiple neurocognitive processes.

\section{Introduction}

The medial frontal cortex (MFC), which includes the anterior cingulate cortex (ACC), has long been implicated in performance monitoring (Gehring et al., 1993; Carter et al., 1998; Botvinick et al., 2001; Alexander and Brown, 2011). Among other cognitive control functions, it is thought to detect the occurrence of errors, and to work in concert with the dorsolateral prefrontal cortex (DLPFC) to subsequently enhance top-down control over the motor system to avoid future errors (Gehring and Knight, 2000; MacDonald et al., 2000; Kerns et al., 2004; Ridderinkhof et al., $2004 a, b)$. It has been suggested that oscillatory activity in the theta $(4-8 \mathrm{~Hz})$ band may be the electrophysiological mechanism underlying these interactions (Luu and Tucker, 2001; Luu et al., 2004; Trujillo and Allen, 2007), reflected by midfrontal theta power and frontal intersite theta phase synchronization $(\mathrm{Ca}-$ vanagh et al., 2009). These and other recent findings (Hanslmayr et al., 2008, Nigbur et al., 2012) have corroborated the idea that

Received Feb. 20, 2012; revised Aug. 14, 2012; accepted Sept. 6, 2012.

Author contributions: J.v.D. and M.XC. designed research; J.v.D. performed research; J.v.D. and M. XC. analyzed data; J.v.D., K.R.R., and M. XC. wrote the paper.

J.v.D. and M. XC. are, and the present work was, supported by a Vidi grant from the Netherlands Organization for Scientific Research (NW0), awarded to M. X C. We thank the reviewers and Ali Mazaheri for their critical comments on an earlier version of this manuscript.

This article is freely available online through the J Neurosci Open Choice option.

Correspondence should be addressed to Joram van Driel, Department of Psychology, The University of Amsterdam, 1018 XA, Amsterdam, The Netherlands. E-mail:.j.vandrie@@uva.nl.

DOI:10.1523/JNEUROSCI.0802-12.2012

Copyright $\odot 2012$ the authors $\quad 0270-6474 / 12 / 3216795-12 \$ 15.00 / 0$ the MFC could better be conceptualized as one important "hub" in a larger network that supports post-error adaptation (Cohen, 2011; Cohen and van Gaal, 2012).

In studying error processing, most of the above studies typically compare two conditions: errors and correct trials. However, qualitatively different kinds of errors may exist that result from and lead to distinct neurocognitive processes (Christ et al., 2000; Steinhauser and Kiesel, 2011; Ham et al., 2012). Importantly, because these different types of errors can be present in one task, but are behaviorally difficult to distinguish, their different patterns of error-related brain activity are averaged together, clouding interpretations of the specific neural mechanisms underlying error monitoring and adaptation.

In long tasks with repetitive trials in a non-arousing environment, the participant's level of sustained attention fluctuates over time (Smallwood and Schooler, 2006; Cohen and Maunsell, 2011): Subjects have attentional lapses that are manifest in increased response time variability (Weissman et al., 2006) and errors (O'Connell et al., 2009a,b). Fluctuations in sustained attention have been linked to alpha $(8-12 \mathrm{~Hz})$ activity over posterior parietal-occipital areas (Dockree et al., 2007; Sadaghiani et al., 2010; Macdonald et al., 2011). For example, increased prestimulus alpha power (O'Connell et al., 2009a,b) and postresponse alpha suppression (Mazaheri et al., 2009) have been associated with errors in the Sustained Attention to Response Test (SART).

Given the above findings of midfrontal theta dynamics related to error monitoring in cognitive control and posterior alpha dy- 

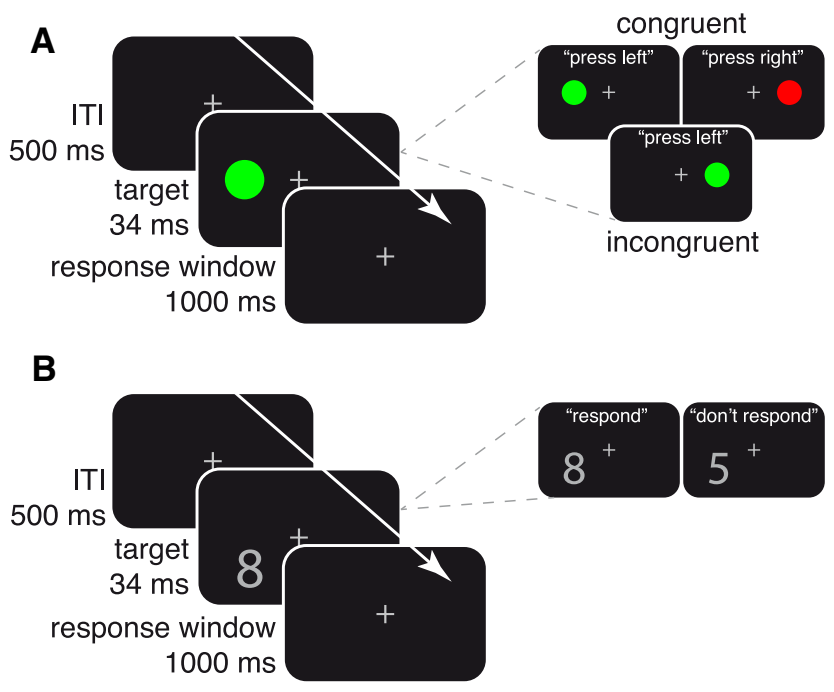

Figure 1. Task design and trial sequence. $\boldsymbol{A}$, Simon task, Experiments 1 and 2. Colors used: red-green and blue-yellow, mapped to either left or right thumb (counterbalanced across subjects), and presented either left or right from fixation. In one third of trials position on the screen and required response was incongruent. These settings were consistent for the different Simon conditions. B, SART Experiment 2. Trials contained digits 1-9 presented in lower left of visual field. One ninth of trials were NoGo (digit5). Other settings were similar to the Simon task.

namics related to sustained attention variability, the goal of this study was to better characterize different error-related neural mechanisms within the same and across different tasks. First, we showed that subtle manipulations of the Simon task [used to study response conflict (Leuthold, 2011)] resulted in varying degrees of theta and alpha oscillatory activity after errors. Second, we showed that errors in the SART [used to study attention lapses (Robertson et al., 1997)] resulted in comparable theta but stronger alpha error-related dynamics. Together, these findings demonstrate that errors may recruit, in varying degrees, different cooccurring neurocognitive processes.

\section{Materials and Methods}

To elucidate theta and alpha oscillatory activity in relation to different types of performance errors, we conducted two experiments: Experiment 1 consisted of three different conditions of the Simon task in the same subjects, and Experiment 2 consisted of the SART and the Simon task in the same subjects (different subjects from Experiment 1). EEG data collection and analyses were similar for both experiments.

\section{Experiment 1}

Subjects. Twenty-nine subjects (age 18-27, six male, six left-handed) from the University of Amsterdam community participated in exchange for 14 euros or course credits. Subjects signed an informed consent document and reported to have normal or corrected-to-normal vision. The study was approved by the local ethics committee; all procedures complied with relevant laws and institutional guidelines. Data from 10 subjects were removed due to either too few errors (below 30 in one or more conditions, corresponding with a required minimum error rate of $5 \%$ per condition) or performance at chance level for one or more stimuli. None of the subjects showed excessive EEG artifacts (see below), thus 19 subjects (four male, four left-handed) were included in the final analyses.

Task. Subjects performed three versions of the Simon task (Simon and Rudell, 1967) that differed only in block length, predictability of trial type, and instructions. The following stimulus and timing parameters were constant across blocks (Fig. 1A). Subjects were instructed to press with, e.g., their left thumb after seeing a blue or yellow circle, and right thumb after seeing a red or green circle. The same colors were used for all subjects and color-response mapping was held constant throughout the three versions of the task (left vs right counterbalanced across subjects).
Targets subtended 0.50 degrees visual angle (dva) and appeared for $34 \mathrm{~ms}$ $8.33 \mathrm{dva}$ left or right from fixation. The inter-trial-interval (ITI) was 500 $\mathrm{ms}$. A gray fixation cross ( $0.25 \mathrm{dva})$ was always present; all stimuli were presented on a black screen. Response conflict is induced when the location of the target stimulus corresponds with the incorrect response hand (e.g., if the blue target, which requires a left-hand response, appears right of fixation). These trials are termed incongruent; congruent trials are those in which the target appears in the same visual hemifield as the required response. One third of trials were incongruent. There was a 1000 $\mathrm{ms}$ window after target onset in which responses were accepted. Feedback on response speed was presented with the words "respond faster!" if subjects did not respond within $750 \mathrm{~ms}$ after stimulus onset, or "too fast, respond to the circle!" if subjects responded faster than $100 \mathrm{~ms}$. Subjects performed a short practice block of 48 trials with randomized congruent and incongruent trials. Feedback on accuracy was presented only in this practice block, after each trial, with the words "wrong" or "correct." Feedback was presented at fixation, for $1000 \mathrm{~ms}$.

The three versions differed in the following instructions and parameters. The General Simon condition consisted of two blocks of 300 trials with congruency randomized over trials, and a self-paced break in between blocks. Subjects were instructed to focus on both accuracy and speed. The Motor Control Simon condition consisted of 17 blocks of 36 trials with randomized congruency, and $20 \mathrm{~s}$ breaks in between blocks. Subjects were instructed to maintain their attention to the task during these short blocks, and to use the breaks to regain their attention. Moreover, subjects were instructed to focus more on speed than on accuracy. The Sustained Attention Simon condition consisted of two blocks of 312 trials with a fixed, predictable order of congruency, which was explicitly told to the subjects: two consecutive congruent trials were always followed by one incongruent trial, and a fixed sequence of left/right responses was repeated every 12 trials. In addition, subjects were instructed to focus on accuracy rather than speed. Subjects always performed the General condition first; the order of the Motor Control and Sustained Attention condition was counterbalanced across subjects.

The motivation behind these manipulations was to maintain similarity across conditions while "tipping the balance" of errors toward being produced by motor control failures (in the Motor Control condition) or attentional lapses (in the Sustained Attention condition). We believe that these mechanisms are mixed in most studies, and are less mixed with these manipulations. Therefore, we expect more quantitative than qualitative differences between the Simon conditions, resulting from the distribution of qualitatively different error types varying in degree.

Active cognitive control processes on the current trial are partly shaped by the type of and performance on the previous trial (Gratton et al., 1992; Kerns et al., 2004; Egner, 2007; Cohen and Cavanagh, 2011). Therefore, we divided trials into separate accuracy conditions, collapsing over Simon-congruency: correct trials following and preceding correct trials $(c \mathrm{Cc})$, correct trials following error trials $(\mathrm{eC})$, and error trials following correct trials (cE). Behavioral analyses were done on all three trial categories; EEG analyses were done on $\mathrm{cCc}$ and cE trials. Because all subjects had more cCc than $\mathrm{cE}$ trials, we selected for each subject a sample of cCc trials with reaction times (RTs) around the mean RT of cE trials, and number of this sample matching the amount of $\mathrm{cE}$ trials. This trial selection procedure ensures that differences between Simon task variants cannot be attributed to trial count, signal-to-noise ratio, or reaction time.

\section{Experiment 2}

Subjects. Seventeen subjects (age 19-23, three male, all right-handed) from the University of Amsterdam community participated for 14 euros or course credit. Subjects signed an informed consent document and reported to have normal or corrected-to-normal vision. The study was approved by the local ethics committee; all procedures complied with relevant laws and institutional guidelines. Data of two subjects were removed due to excessive channel and/or EMG artifacts.

Tasks. The experiment consisted of two tasks: the General Simon task and an adapted version of the Sustained Attention to Response Test, or 
SART (Mazaheri et al., 2009; O'Connell et al., 2009a). The General Simon task was the same as the one used in Experiment 1. Subjects always performed the General Simon task first.

Stimuli in the SART consisted of the digits " 1 " through " 9 " and were presented randomly in gray color in the lower left visual field, with an eccentricity of $3.15 \mathrm{dva}$. Subjects were instructed to respond with their dominant hand to all digits (Go trials) except "5," at which they should inhibit their response (NoGo trial). On each trial the digits varied randomly in size (0.84-1.17 dva) and font. This was to ensure that subjects processed the identity of the digits rather than focusing on specific perceptual features. A gray fixation cross (size $0.25 \mathrm{dva}$ ) was always present. Trial timing parameters and feedback on response speed were similar to the Simon task (see above and Fig. $1 B$ ). Subjects performed a short practice block of 24 trials. The SART contained a maximum of 6 blocks of 324 trials, where each digit was presented 36 times per block. The task ended after the second through fifth block if the subject had made $>50$ false alarms (erroneously responding on a NoGo trial) in total. Trial selection procedure of error and correct trials was similar to Experiment 1.

\section{EEG data collection}

EEG data were acquired at $512 \mathrm{~Hz}$ from 64 channels (using a BioSemi ActiveTwo system; biosemi.com) placed according to the international 10-20 system, and from both earlobes (used as reference). Offline, EEG data were high-pass filtered at $0.5 \mathrm{~Hz}$ and epoched from -1.5 to $2 \mathrm{~s}$ surrounding each trial (to avoid edge artifacts resulting from wavelet filtering, see below). All epochs were visually inspected and those containing EMG or other artifacts not related to eye-blinks were manually removed. After rejection, Experiment 1 contained on average $66 \mathrm{cE}$ and 66 cCc trials (minimum/maximum across subjects: 33/131, 31/130, respectively). In Experiment 2, the Simon task contained on average 77 $(35 / 109)$ cE and 79 (37/111) cCc trials, and the SART 50 (37/62) and 51 (39/63), respectively. Independent components analysis was performed on the remaining epochs using the eeglab package (Delorme and Makeig, 2004) in Matlab (The MathWorks). Components that contained oculomotor artifacts (e.g., blinks) or other artifacts that could be clearly distinguished from brain-driven EEG signals (e.g., a bridge between neighboring channels) were subtracted from the data. Subsequently, all EEG data were spatially filtered using the current source density (CSD) approach (Kayser and Tenke, 2006). CSD as used here is equivalent to the surface Laplacian, and has previously been applied to sharpening EEG topography and performing synchronization analyses (Cavanagh et al., 2009, 2010; Cohen et al., 2009; Cohen, 2011). CSD accentuates local effects while filtering out distant effects due to volume conduction [deeper brain sources that project onto multiple electrodes, thereby obscuring neurocognitively modulated long-range functional connectivity (Srinivasan et al., 2007; Winter et al., 2007)]. After CSD, EEG data in each epoch were time-locked to the button press.

\section{EEG time-frequency decomposition}

The response-locked epoched EEG time series were decomposed into their time-frequency representation with custom written Matlab routines (Cohen et al., 2008) by convolving them with a set of Morlet wavelets $\left(e^{i 2 \pi t f} e^{-t^{2} /\left(2 \sigma^{2}\right)}\right.$, where $i$ is the complex operator, $t$ is time, $f$ is frequency ranging from 1 to $50 \mathrm{~Hz}$ in 50 logarithmically spaced steps, and $\sigma$ defines the width of each wavelet, according to $4 / 2 \pi f$ ). From the resulting complex signal, an estimate of frequency-band-specific power at each time point was defined as the squared magnitude of the result of the convolution $Z_{\mathrm{t}}\left(\operatorname{real}\left[z_{\mathrm{t}}\right]^{2}+\operatorname{imag}\left[z_{\mathrm{t}}\right]^{2}\right)$, and an estimate of frequency-bandspecific phase at each time point was taken as the angle of the convolution result. Power was subsequently decibel normalized $(\mathrm{dB}$ power $=$ $10^{*} \log 10$ [power/baseline]), where for each channel and frequency the condition-averaged power signal during an interval of -400 to $-100 \mathrm{~ms}$ prestimulus served as baseline activity. Interchannel phase synchrony (ICPS) reflects the similarity between pairs of channels of their timefrequency phase values averaged over trials. ICPS is computed as follows:

$$
\left|\frac{1}{n} * \sum_{\mathrm{t}=1}^{n} e^{i\left(\phi_{\mathrm{jt}}-\phi_{\mathrm{k})}\right)}\right|
$$

where $n$ is the number of trials, $\Phi_{j t}$ and $\Phi_{k t}$ are the phase angles of electrodes $j$ and $k$ at each time point $t$. Thus, ICPS varies between 0 (no phase synchrony between channels) and 1 (identical phase angles between channels) for each frequency band and time point. Note that ICPS is different from other functional connectivity measures, such as the phase-lag index (Stam et al., 2007), but similar to the phase-locking value (Lachaux et al., 1999).

\section{Selection of electrodes, frequency bands and time-windows} of interest

For our statistical analyses, we started with a selection procedure that was orthogonal to potential condition differences. First, we inspected activity in the a priori chosen frequency bands of theta $(4-8 \mathrm{~Hz})$ and alpha $(8-12$ $\mathrm{Hz}$ ), collapsed over Simon conditions of Experiment 1. To pick electrodes of interest, we next plotted error-related $(\mathrm{cE}-\mathrm{cCc})$ topographical activity at three subsequent time points after response $(0 \mathrm{~ms}, 250 \mathrm{~ms}, 500$ ms; see Fig. $4 A$ ). Note that this electrode selection procedure was thus purely based on the comparison of error versus correct trials, which should reveal error-processing regions regardless of Simon condition. This comparison revealed clear activity at electrode FCz for theta. In the alpha band, activity was more distributed over posterior parts of the scalp without clear local maxima. To cover bilateral parieto-occipital areas [known to be involved in error processing during attention tasks (Vanni et al., 1997)], we chose electrodes PO3/PO4 for our alpha analyses. Next, specific time windows were chosen based on the peak activity in timefrequency power plots of these electrodes for $\mathrm{cCc}, \mathrm{cE}$, and $\mathrm{cCc}-\mathrm{cE}$ activity (see Fig. 4B). For ICPS analyses, we initially picked the same timefrequency windows and electrodes as used for the power analyses. $\mathrm{FCz}$ and the average of PO3 and PO4 thus served as "seeds" for theta and alpha synchronization, respectively. For Experiment 2 we then used these same time-frequency windows and electrodes for both power and ICPS analyses.

\section{Statistical analyses}

For each subject the average activity ( power/ICPS) from these electrodes and time-frequency windows was computed and entered into 2 ( $\mathrm{cCc}$ and cE trials) by 3 (Simon conditions) repeated-measures ANOVAs for Experiment 1 , and 2 ( $\mathrm{cCc}$ and $\mathrm{cE}$ trials) by 2 (Simon vs SART) repeatedmeasures ANOVAs for Experiment 2. In all ANOVAs, if the sphericity assumption was violated, Greenhouse-Geisser corrected $p$ values are reported with original degrees of freedom. Additional two-tailed $t$ tests were used to examine directional effects. Correlations between brain activity and behavior were computed with Spearman's $\rho$.

\section{Results \\ Experiment 1 \\ Behavior}

On average, subjects responded correctly on $84.6 \%$ ( \pm SEM, 1.05$)$ of total trials. Accuracy differed across conditions $\left(F_{(2,17)}=12.51, p<\right.$ $0.001)$, with highest accuracy in the Sustained Attention condition. The three conditions also differed in $\operatorname{RT}\left(F_{(2,17)}=134.6, p<0.001\right)$, with the General condition showing the slowest, the Motor Control condition intermediate, and the Sustained Attention condition the fastest responses. All conditions induced the "Gratton effect" (Gratton et al., 1992): a significant interaction between previous and current trial congruency for accuracy and RT in the General condition (respectively, $F_{(1,18)}=62.19, p<0.001 ; F_{(1,18)}=81.64, p<0.001$ ) and the Motor Control condition $\left(F_{(1,18)}=58.39, p<0.001 ; F_{(1,18)}\right.$ $=83.32, p<0.001)$, and Sustained Attention condition $\left(F_{(2,17)}=\right.$ $\left.18.51, p<0.001 ; F_{(2,17)}=21.20, p<0.001\right)$. In general, incongruent trials following congruent trials had the lowest accuracy and slowest responses, which is in accordance with previous findings (Egner, 2007; Cohen and Cavanagh, 2011). However, conflict effects were lowest in the Sustained Attention condition as indicated by a significant interaction between condition and congruency-sequence for both accuracy $\left(F_{(4,15)}=9.74, p<\right.$ $0.001)$ and $\operatorname{RT}\left(F_{(4,15)}=7.45, p=0.001\right)$. 
This difference in degree of conflict was also reflected in response speed of error relative to correct trials. As can be seen in Figure 2A1, the General and Motor Control condition showed "error speeding" (defined by lower RT on cE compared with cCc trials) while the Sustained Attention condition showed the reverse pattern (trend toward trial-type by condition interaction: $F_{(2,17)}=3.5, p=0.059$; significant error-speeding only in the General condition: $t_{(18)}=2.8, p=0.011$ ). Error speeding has been explained as resulting from a competing, faster processing of the irrelevant stimulus location, which at incongruent trials leads to errors (Ridderinkhof, 2002; Burle et al., 2005). This is often investigated by the conditional accuracy functions (Gratton et al., 1992; van den Wildenberg et al., 2010), which here revealed that the Simon conditions indeed differed on these speedaccuracy dynamics (Fig. $2 B$, quintile by condition interaction: $F_{(8,11)}=10.08, p<$ 0.001). Specifically, fast responses (i.e., first quintile of the RT-distribution) on incongruent trials were below chance level for the General $\left(t_{(18)}=-3.04, p=0.007\right)$ and Motor Control $\left(t_{(18)}=-2.45, p=\right.$ $0.025)$ condition, suggesting response capture by the irrelevant location (Ridderinkhof, 2002). In contrast, for the Sustained Attention condition, accuracy was above chance on fast trials $\left(t_{(18)}=4.51, p<\right.$ 0.001 ), suggesting that this condition elicited fewer "impulsive" errors. Importantly, all conditions showed posterror slowing (Fig. 2A2): eC trials (correct trials after error trials) were slower than cCc trials (main effect of trial type: $F_{(1,18)}=14.82, p=0.001$; no differences between conditions).

EEG: power

All electrodes used for in-depth analyses were selected based on a condition-orthogonal contrast (see Materials and Methods for details). Figures 4 and 5 show the main effects of trial type (cE$\mathrm{cCc}$ ) on oscillatory power for the three Simon conditions averaged together (Fig. 4) and for the conditions separately (Fig. 5), revealing a robust error-related midfrontal theta increase immediately after the response, and a later parieto-occipital alpha suppression effect. In a 50-300 ms post-response time window, cE trials elicited stronger theta power than cCc trials at electrode $\mathrm{FCz}$ $\left(F_{(1,18)}=126.7, p<0.001\right)$. This effect differed across conditions $\left(F_{(2,17)}=3.97, p=0.032\right)$, with the Sustained Attention condition showing the least error-related theta (Fig. 5A3). Follow-up $t$ tests confirmed a significant difference in $\mathrm{cE}-\mathrm{cCc}$ theta power between Motor Control and Sustained Attention $\left(t_{(18)}=2.39\right.$, $p=0.028)$ in this time window.

At electrodes $\mathrm{PO} 3 / \mathrm{PO} 4$, a time window of $150-500 \mathrm{~ms}$ postresponse exhibited stronger alpha suppression for $\mathrm{cE}$ trials than $\mathrm{cCc}$ trials $\left(F_{(1,18)}=21.39, p<0.001\right)$. There was no interaction with condition, although as can be seen in Figure $5 B$, the difference between conditions was in the duration rather than degree of error-related alpha suppression; these temporal dynamics were averaged out in the condition-averaging approach (see Materials and Methods). We thus performed an additional exploratory

\section{A1}

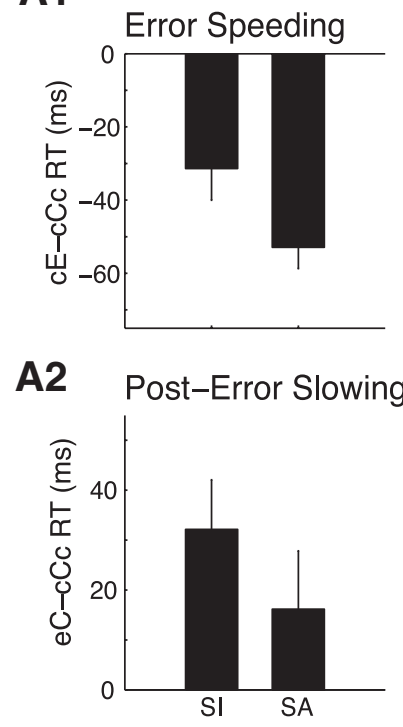

Figure 3. Behavioral results from Experiment 2.A, RT effects according to condition and accuracy on current and previous trial, reflecting error speeding (A1) and posterror slowing (A2). B, Conditional accuracy functions showing accuracy as a function of quintiles of the RT-distribution, for Simon congruent (CG; black dashed line, open circles), Simon incongruent (IC; black closed line, filled squares), and SART (gray closed line, filled squares). Error bars denote SEM. SI, Simon task; SA, SART.

ANOVA on a 400-600 ms postresponse window, which revealed both a main effect of trial type $\left(F_{(1,18)}=6.37, p=0.021\right)$ and a significant interaction effect with condition $\left(F_{(2,17)}=8.36, p=\right.$ 0.001). A follow-up $t$ test indicated that the Sustained Attention 
A
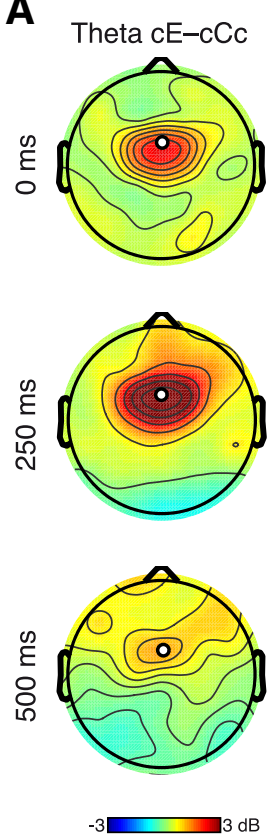

Alpha cE-cCc
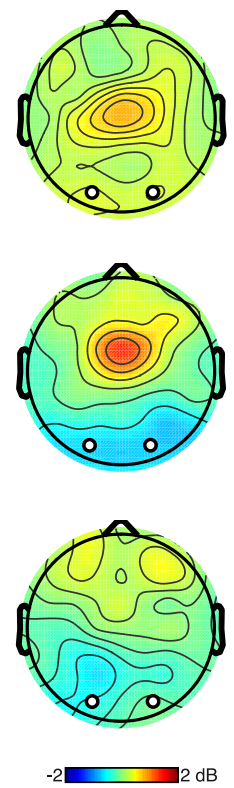

B

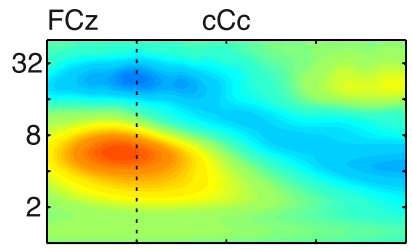

cE

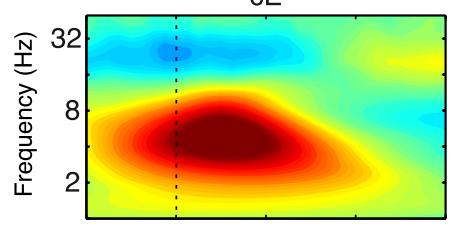

$\mathrm{cE}-\mathrm{cCc}$

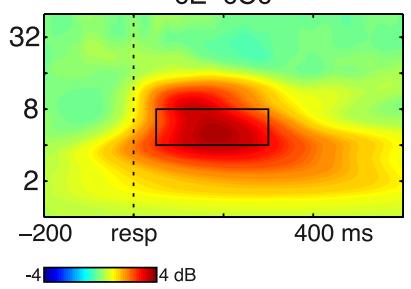

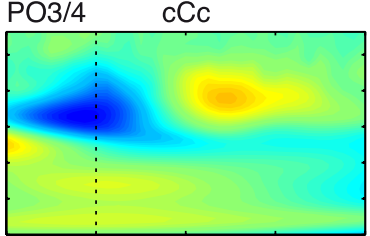

$\mathrm{cE}$
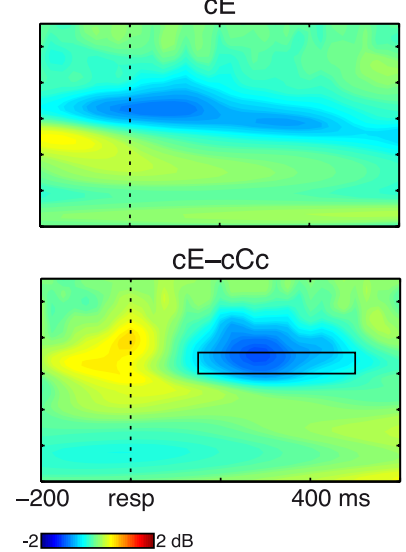

Figure 4. Response locked oscillatory power averaged over the different Simon conditions in Experiment 1, for correct and error trials, and error-related activity ( $(C E-c C c)$. $A$, Theta (4 - $8 \mathrm{~Hz}$; left) and alpha (8-12 Hz; right) power over space, from top to bottom at $0 \mathrm{~ms}, 250 \mathrm{~ms}$, and $500 \mathrm{~ms}$ after response. Black-white disks denote electrodes plotted in B. $\boldsymbol{B}$, Power in $\mathrm{dB}$ relative to baseline for electrode FCZ (left) and for pooled electrodes P03/P04 (right). Black line boxes in bottom row show time-frequency windows of interest used for ANOVA.

condition showed a more sustained alpha suppression than the Motor Control condition $\left(t_{(18)}=3.41, p=0.003\right.$; Fig. 5B3).

\section{EEG: synchronization}

We next examined whether in addition to power, error-related theta and alpha synchronization would also differentiate between the Motor Control and Sustained Attention condition. As "seed" electrodes for synchronization, we used the same electrodes as defined by the power analyses ( $\mathrm{FCz}$ and the average of $\mathrm{PO} 3 / 4$ ). Thus, seed-electrode selection was also orthogonal to condition differences. In the same 50-300 ms window used for the analysis of theta power, a Simon condition contrast of cE-cCc theta ICPS showed general clusters of $\mathrm{FCz}$-connectivity with lateral frontal and medial posterior sites. For Motor Control compared with Sustained Attention there was specifically higher theta synchronization with F5 and F6 and POz. Next, in the same 400-600 ms window used for the analysis of alpha power, we found for a Simon condition contrast of $\mathrm{cE}-\mathrm{cCc}$ alpha ICPS, connectivity between $\mathrm{PO} 3 / \mathrm{PO} 4$ and a right frontal cluster. Specifically, FC4 exhibited higher alpha synchronization for Sustained Attention compared with Motor Control (Fig. 6A1,B1).

Separate 2 (cE vs cCc) by 3 (Simon conditions) ANOVAs for theta and alpha confirmed these observations. Average $\mathrm{FCz}-$ F5/F6 theta synchronization within 50-300 ms postresponse was significantly higher at $\mathrm{cE}$ than $\mathrm{cCc}$ trials $\left(F_{(1,18)}=16.81, p=\right.$ $0.001)$, and this effect differed across conditions $\left(F_{(2,17)}=6.70\right.$, $p=0.003)$. Figure $6 A 2$ shows that this effect was highest for Motor Control $\left(t_{(18)}=4.20, p=0.001\right)$, and absent for Sustained Attention $\left(t_{(18)}=0.97, p=0.35\right)$, and the difference between these conditions was significant $\left(t_{(18)}=3.47, p=0.003\right)$. For long-range theta synchronization between $\mathrm{FCz}$ and $\mathrm{POz}$, we also found within 50-300 ms a significant main effect of trial type $\left(F_{(1,18)}=5.77, p=0.027\right)$, and a significant interaction with condition $\left(F_{(2,17)}=4.43, p=0.019\right)$, which was driven by greater synchronization between these electrodes in Motor Control compared with Sustained Attention $\left(t_{(18)}=2.63, p=0.017\right)$. The latter condition did not show $\mathrm{cE}-\mathrm{cCc}$ theta synchronization between these channels $\left(t_{(18)}=-0.85, p=0.41\right.$; Fig. 6A2).

Subsequently, we examined frontoparietal network activity, quantified as alpha synchronization between electrodes PO3/PO4 and FC4. A similar ANOVA on average alpha ICPS within 400-600 $\mathrm{ms}$ between these electrodes initially did not give significant differences between $\mathrm{cE}$ and $\mathrm{cCc}$ trials $\left(F_{(1,18)}=0.025, p=0.88\right)$, nor was there an interaction effect with condition $\left(F_{(2,17)}=2.67, p=0.083\right)$. Note that the choice of time-window for this analysis was based on the exploratory power analysis described above. We thus conducted an additional exploratory ANOVA on a wider time window, upon inspection of the line plot in Figure $6 B 2$ of alpha ICPS over time. Averaging over $200-700 \mathrm{~ms}$, there was a significant trial type by condition interaction $\left(F_{(2,17)}=5.22, p=0.010\right)$, although there was no main effect of trial type. This partly resulted from initial lower ICPS for cE relative to cCc trials in Motor Control (200-500 ms, $t_{(18)}$ $=-2.39, p=0.028)$, followed by higher ICPS for Sustained Attention $\left(500-700 \mathrm{~ms}, t_{(18)}=4.58, p<0.001\right)$, within this time window, thus canceling out a main effect. Follow-up $t$ tests confirmed that the difference between the two conditions within 200-700 ms was significant $\left(t_{(18)}=2.89, p=0.010\right)$. To evaluate the right-lateralized condition difference in alpha ICPS, the right plot in Figure $6 B 2$ shows $\mathrm{cE}-\mathrm{cCc}$ alpha ICPS between PO3/PO4 and FC3 with no clear differences between conditions. However, there was a main effect trial type $\left(F_{(1,18)}=6.47, p=0.020\right)$ reflecting lower average alpha ICPS between these channels for $\mathrm{cE}$ compared with cCc trials, 200$700 \mathrm{~ms}$ after response.

It has been argued that measured synchronization at the sensor level can in principle reflect spuriously coupled activity due to volume conduction from a single source (Nunez et al., 1997). Other more conservative measures of functional connectivity in EEG have been proposed, such as the phase-lag index (Stam et al., 2007). To control for this potential confound, we conducted a control analysis to show that the differences in phase angle between channels of interest, in the time-frequency windows with 
A1 General

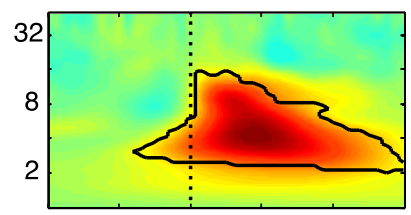

Motor Control

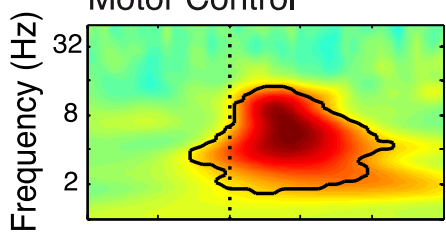

Sustained Attention

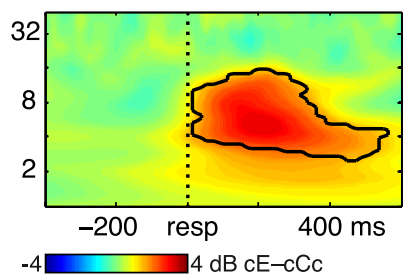

A2
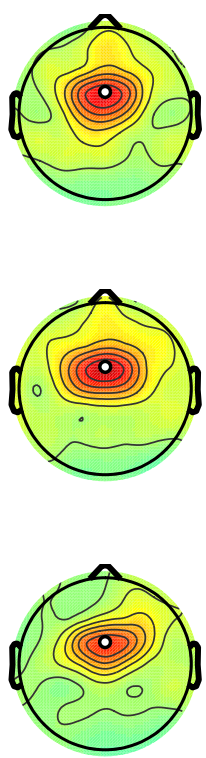

B1 General

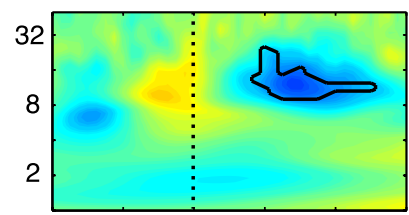

Motor Control

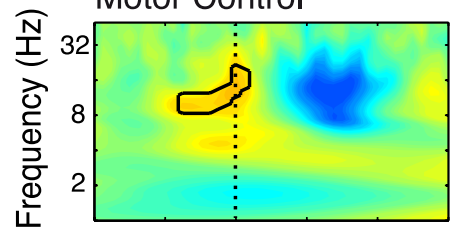

Sustained Attention

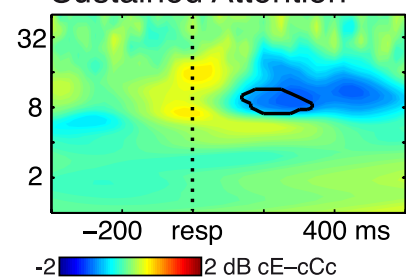

B2
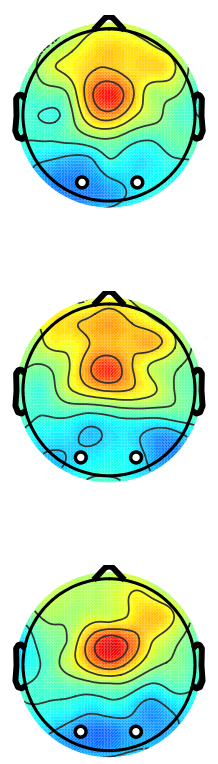

A3

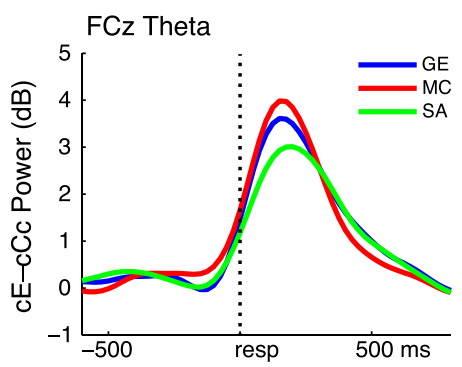

B3

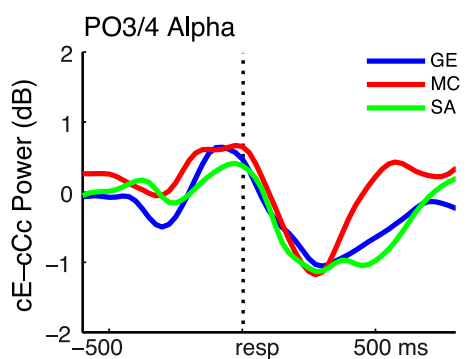

Figure 5. Error-related ( $\mathrm{CE}-\mathrm{cCc}$ trials) oscillatory power shows differential theta and alpha dynamics for the different Simon conditions in Experiment 1. A1, Time-frequency power plots for electrode $\mathrm{FCz}$ for the different conditions (rows). Black lines enclose regions of contiguous pixels that were significantly different from baseline at $p<0.0001$, for at least 200 ms and three consecutive frequencies. B1, Same as in $\mathbf{A 1}$, for pooled electrodes P03/P04, with $p<0.001$. A2, Topographical power plots for the theta band averaged over a postresponse time window of $50-300$ ms. Black-white disks denote electrodes plotted in $\mathbf{A 1}$. B2, Same as in $\mathbf{A 2}$, for alpha $\mathbf{1 5 0}-500 \mathrm{~ms}$. $\mathbf{A 3}$, Line plots of FCz theta activity over time for the different conditions. $\boldsymbol{B}$, Same as in $\boldsymbol{A}$, for P03/P04 alpha.

significant ICPS effects between Simon conditions, were not distributed around zero or $\pi$ (which purely volume conducted apparent synchronization would predict). First, we computed for each subject, per Simon condition, the phase angle difference over time ( -500 to $1000 \mathrm{~ms}$ ) between the selected electrodes for theta $(6 \mathrm{~Hz}$; FCz-F5, FCz-F6, FCz-POz) and alpha (10 Hz; PO3FC4, PO4-FC4), at the single trial (cE and cCc) level. Subsequently, we tested within-subject and over trials, whether these angles were significantly different from zero or $\pi$ using the circular $\mathrm{V}$-test (a modified version of the Rayleigh test for uniformity of circular data; see Fisher, 1996) from the circstat toolbox (Berens, 2009). Here, the alternative hypothesis states that angles are not uniformly distributed but instead have a specified mean direction. We used zero and $\pi$ as mean directions; rejecting the null-hypothesis $(p<0.05)$ would thus be indicative of volume conduction. However, averaging over subjects, we observed only high $p$ values $(>0.50$ for zero, $>0.10$ for $\pi$ ). In addition, our findings of no error-related theta interchannel synchrony in the Sustained Attention condition, and absence of error-related power effects in target electrodes, provides further evidence against volume conduction accounting for the synchronization results.
Cross-subject correlations

To test whether the above measures of error-related theta and alpha activity would share variance in terms of individual differences, we computed cross-subject Spearman's rank correlations for the different bands, brain measures, and behavioral results. First, we correlated power and ICPS in the same time-frequency windows that showed condition differences (see above) in these EEG measures. Only in the Motor Control condition, $\mathrm{cE}-\mathrm{cCc}$ theta power at electrode $\mathrm{FCz}$ correlated positively across subjects with $\mathrm{CE}-\mathrm{cCc}$ theta phase synchronization between $\mathrm{FCz}$ and F5/F6 $\left(r_{(19)}=0.71, p=0.001\right)$ and between FCz and POz $\left(r_{(19)}=0.60\right.$, $p=0.007)$. In the General and Sustained Attention condition, these correlations were nonsignificant (all $p>0.05$; Fig. $7 A$ ). Correlations with alpha band activity were not significant, nor were there correlations between alpha and theta error-related activity measures. These null effects are consistent with a previous study that found no significant correlation between posterror alpha power and ERN magnitude (Carp and Compton, 2009).

In a next step, we examined whether oscillatory dynamics of theta and alpha on $\mathrm{cE}$ trials would predict reaction time perfor- 
A1

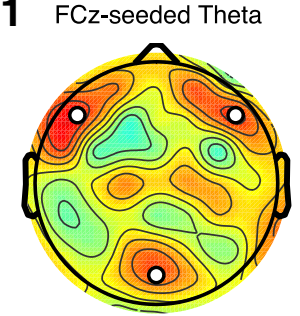

B1
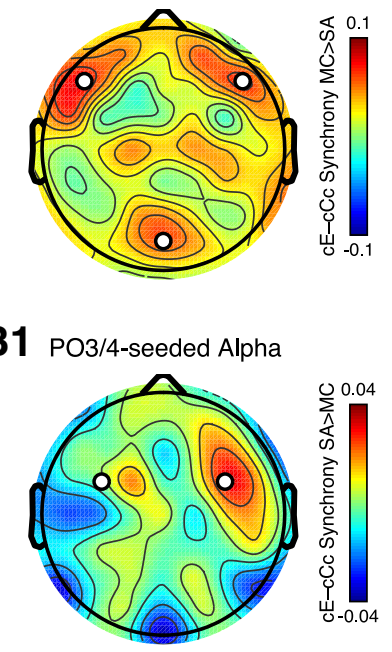

A2

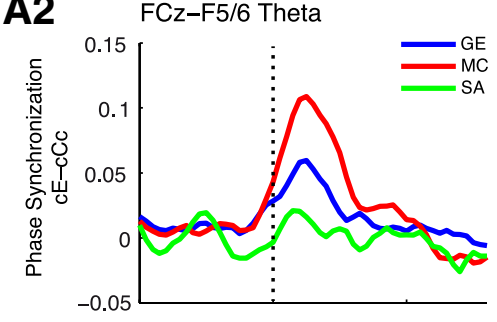

B2

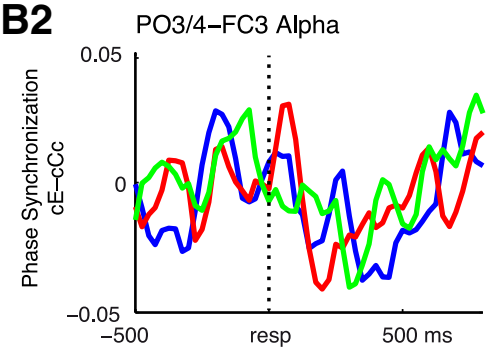

FCz-POz Theta

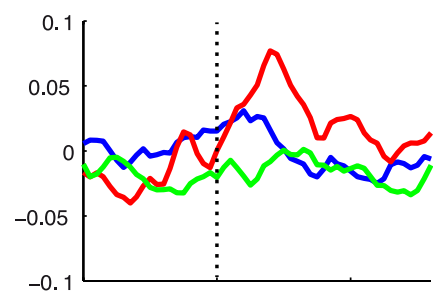

PO3/4-FC4 Alpha

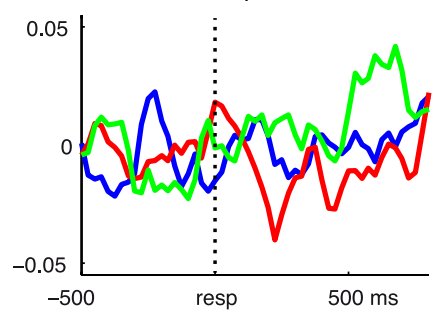

Figure 6. Error-related (CE- CCC trials) interchannel phase synchronization shows differential long-range functional connectivity dynamics for the different Simon conditions in Experiment 1.A1, Topographical difference maps of $\mathrm{FCZ}$-seeded theta synchronization, for Motor Control more than Sustained Attention, over a 50-300 ms postresponse time window. Black-white disks denote target electrodes plotted in A2. B1, As in A1, P03/P04-seeded alpha synchronization for Sustained Attention more than Motor Control, $400-600$ ms. A2, Line plots of error-related theta ICPS over time for the different conditions. $B 2$, As in A2, for alpha ICPS.
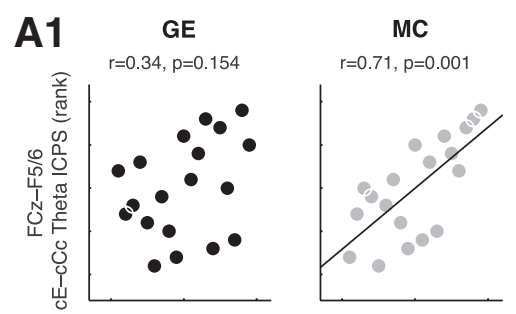

A2
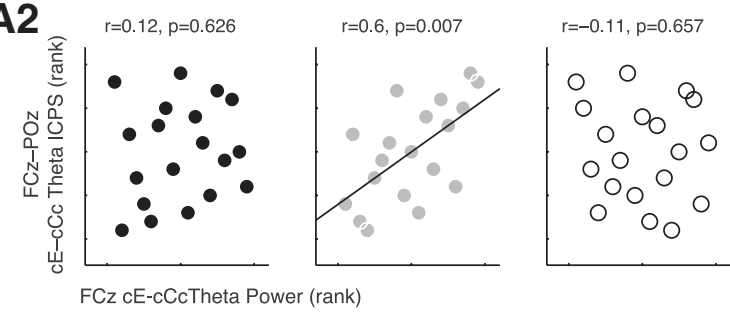

B
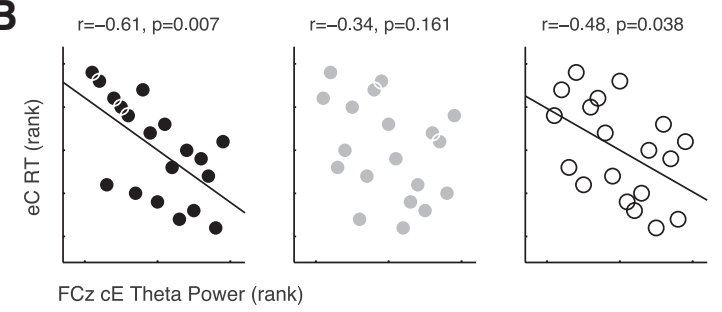

Figure 7. Cross-subject rank correlations for the different Simon conditions. A1, Errorrelated $(\mathrm{CE}-\mathrm{CC})$ interchannel theta phase synchrony between $\mathrm{FCZ}$ and $\mathrm{F} 5 / \mathrm{F} 6$ correlates with error-related theta power at $\mathrm{FCZ}$ only in the Motor Control condition. $\boldsymbol{A}$, Same as in $\boldsymbol{A}$, for FCz-POz ICPS. B, FCz theta power at error trials predicts reaction time on subsequent correct trials only in the General and Sustained Attention condition (lower RT rank means faster response).

mance on subsequent correct $(\mathrm{eC})$ trials, which would reflect a neural mechanism underlying posterror performance enhancement (Cohen et al., 2009; Cavanagh et al., 2009; Manuel et al., 2012). Theta power over electrode FCz showed this relationship, however, surprisingly only in the General and Sustained Atten- tion condition $\left(r_{(19)}=-0.61, p=0.007\right.$; and $r_{(19)}=-0.48, p=$ 0.038 , respectively; Fig. $7 B$ ). These negative correlations imply that subjects with on average higher FCz theta power at $\mathrm{cE}$ trials, responded faster on the next eC trial in these Simon conditions. This relation was not statistically reliable for the Motor Control condition, although the direction of the correlation was also negative $\left(r_{(19)}=-0.34, p=0.16\right)$.

\section{Experiment 2}

\section{Behavior}

In the Simon task, subjects were correct on $81.7 \%$ ( \pm SEM 1.9) of trials. In the SART subjects committed false alarms at $52.3 \%$ ( \pm SEM 4.0) of all NoGo trials. Subjects responded faster in the SART than in the Simon task $\left(t_{(14)}=8.83, p<0.001\right.$; Fig. $\left.3 B\right)$. The Simon task elicited response conflict, as indicated by a significant congruency sequence (i.e., "Gratton") effect on RT $\left(F_{(1,14)}=24.06, p<0.001\right)$ and accuracy $\left(F_{(1,14)}=42.11, p<\right.$ $0.001)$. In addition, errors in the Simon task were mostly elicited by the incongruent stimulus location at the fast end of the RT distribution (Fig. $3 B$, quintile by congruency interaction: $F_{(4,11)}$ $=58.55, p<0.001$ ). Both tasks showed error speeding (Simon: $t_{(14)}=4.67, p<0.001$; SART: $\left.t_{(14)}=11.73, p<0.001\right)$, which was stronger in the SART (trial-type by task interaction: $F_{(1,14)}=$ $5.71, p=0.032$ ). In addition, only the Simon task showed posterror slowing $\left(t_{(14)}=4.17, p=0.001\right.$; SART: $t_{(14)}=1.79, p=$ 0.096).

\section{EEG: power}

As in Experiment 1, we observed strong error-related (cE-cCc) theta activity at electrode $\mathrm{FCz}$, followed by posterior alpha suppression. As can be seen in Figure 8A, midfrontal theta power was highly similar across the two tasks (although in the SART, it also encompassed lower frequencies in the delta $[\sim 2 \mathrm{~Hz}]$ range). An ANOVA on the same postresponse time window that we used for the theta analyses in Experiment $1(50-300 \mathrm{~ms})$ confirmed this (main effect of trial type: $F_{(1,14)}=63.57, p<0.001$; no significant interaction with condition, $\left.F_{(1,14)}=1.27, p=0.28\right)$. However, the SART did show a topographical distribution of theta activity that was slightly more anterior and less focal around FCz (Fig. 
A1

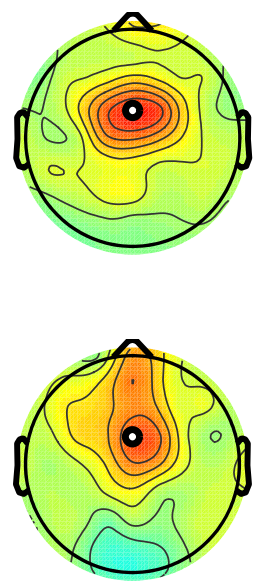

B1
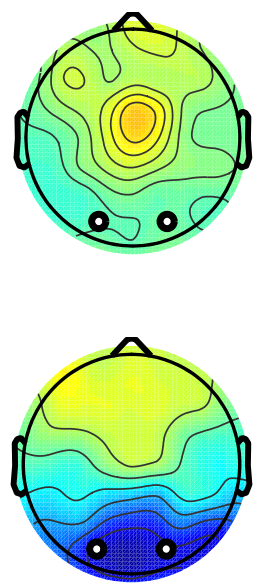

A2

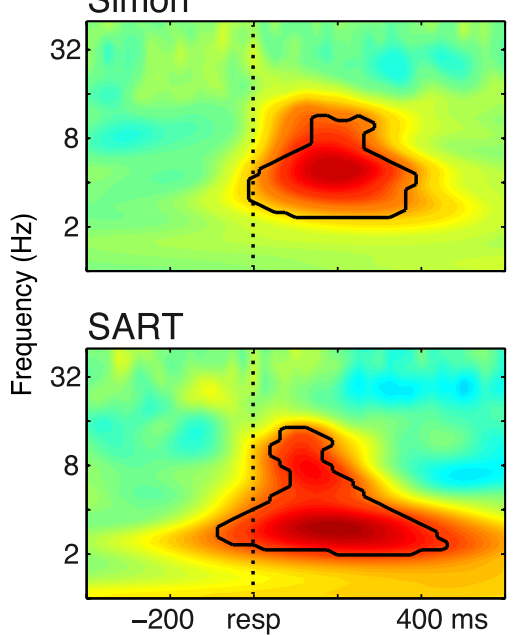

B2 Simon

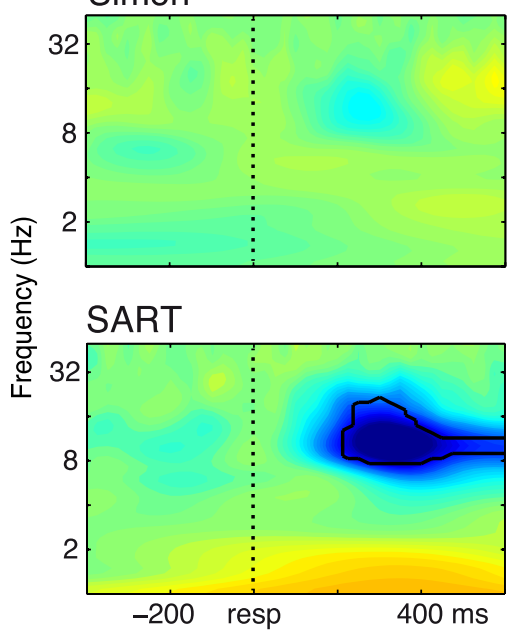

A3

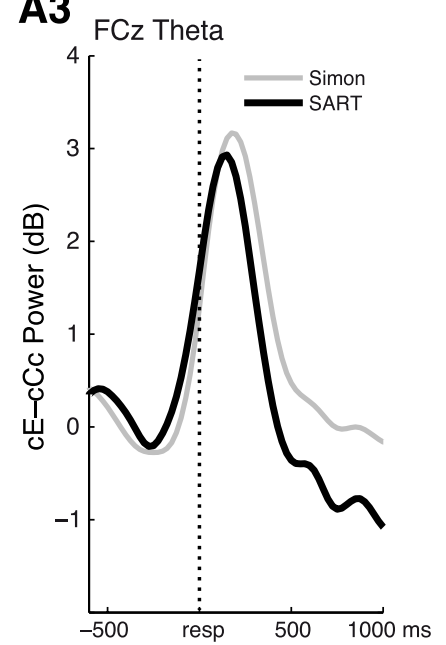

B3

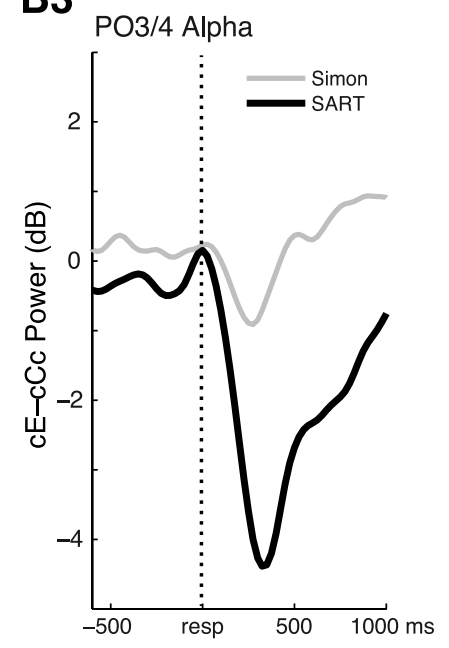

Figure 8. Error-related (CE-cCctrials) oscillatory power shows similar theta but strongly differing alpha dynamics for Simon versus SART in Experiment 2. A1, Topographical power plots for the theta band averaged over a postresponse window of $50-300 \mathrm{~ms}$, for Simon (top) and SART (bottom). Black-white disks denote electrodes plotted in $\boldsymbol{A 2}$. B1, Same as in A1, for alpha 150 -500 ms. A2, Time-frequency power plots for electrode FCz for Simon (top) and SART (bottom). Black lines enclose regions of contiguous pixels that were significantly different from baseline at $p<0.0001$. B2, Same as in A2, for pooled electrodes P03/P04. A3, Line plots of FCz theta activity over time for Simon (gray) and SART (black). B3, Same as in A3, for P03/P04 alpha.

$8 A 1)$. Indeed, post hoc $t$ tests on all channels of error-related theta differences between Simon and SART revealed a spatial difference around $\mathrm{AFz}$ ( $p=0.008$; uncorrected for multiple comparisons).

However, the most notable difference between the tasks resided in posterior alpha suppression after errors compared with correct trials (Fig. 8 B). In a time window of 150-500 ms after the response (same window used for alpha analyses in Experiment 1), the SART showed a stronger error-related $(\mathrm{cE}-\mathrm{cCc})$ decrease of alpha activity at electrodes PO3/4 than the Simon task $\left(F_{(1,14)}=\right.$ $33.13, p<0.001)$, which was also clearly revealed in the topographical distribution of error-related alpha (Fig. 8B1). Follow-up $t$ tests confirmed that the alpha suppression effect was absent in the Simon task $\left(t_{(14)}=1.18, p=0.26\right)$, contrary to the alpha power results of the General Simon condition in Experiment 1 .

\section{EEG: synchronization}

A contrast of $\mathrm{cE}-\mathrm{cCc}$ theta ICPS revealed the same clusters of FCz-seeded connectivity as in Experiment 1 (Fig. 9A1). However, although the SART and Simon task did not seem to differ in terms of midfrontal theta power after errors, SART showed a stronger error-related increase in theta synchronization between $\mathrm{FCz}$ and $\mathrm{F} 5 / 6\left(F_{(1,14)}=14.27, p=0.002\right)$, and $\mathrm{FCz}$ and $\mathrm{POz}\left(F_{(1,14)}=7.35\right.$, $p=0.017$; same target electrodes and time window as in Experiment 1) than the Simon task. Surprisingly, and in contrast to Experiment 1, the Simon task did not show cE-cCc theta synchrony between these channels $\left(t_{(14)}=0.42, p=0.68, t_{(14)}=\right.$ $0.11, p=0.92$, respectively; Fig. 9A2).

Next, we examined whether similar frontoparietal alpha network activity that we observed in the Sustained Attention condition in Experiment 1, would also be present in the SART. However, in the same time window that showed the strong task difference in alpha power suppression, a clear pattern of PO3/4seeded cE-cCc alpha ICPS was absent (Fig. 9B). Moreover, phase synchrony with FC4 (the target electrode found in Experiment 1) did not show an error-related effect $\left(F_{(1,14)}=1.23, p=0.29\right)$, nor an interaction with task $\left(F_{(1,14)}=0.63, p=0.44\right)$. A line plot of PO3/4-FC4 synchrony did seem to indicate stronger alpha connectivity for SART compared with Simon (Fig. 9B2, right), but an exploratory additional ANOVA on a -200 to $150 \mathrm{~ms}$ time win- 
A1
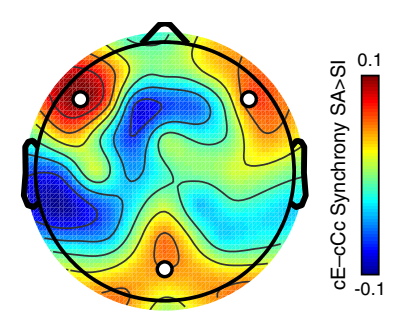

B1 PO3/4-seeded Alpha
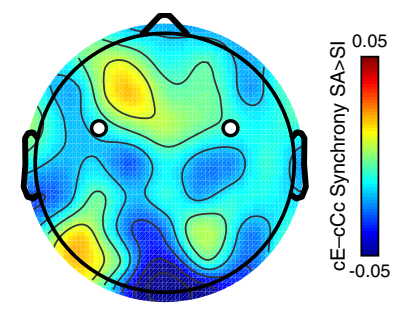

A2

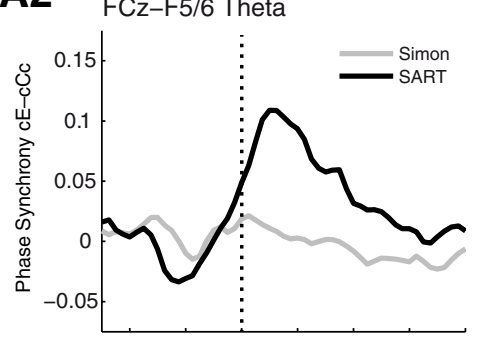

B2

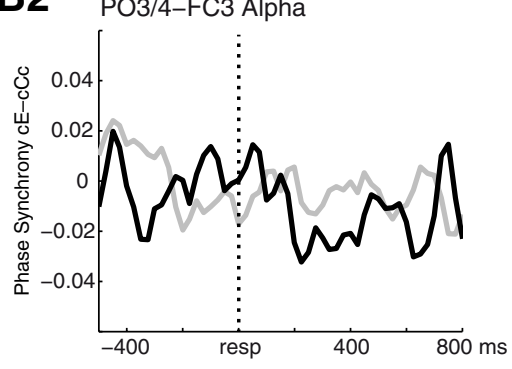

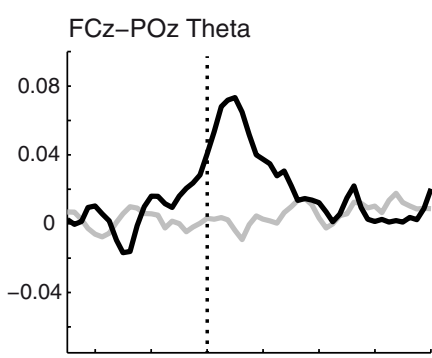

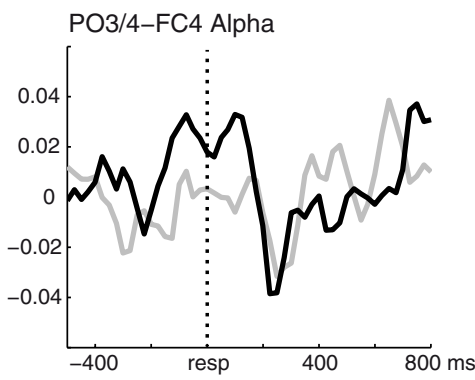

Figure 9. Error-related (CE- $c(C$ trials) interchannel phase synchronization shows differential long-range functional connectivity dynamics for Simon versus SART in Experiment 2. A1, Topographical difference maps of FCz-seeded theta synchronization, for SART more than Simon, over a 50-300 ms postresponse time window. Black-white disks denote target electrodes plotted in $A \mathbf{2}$. B1, As in A1, P03/P04-seeded alpha synchronization for SART more than Simon, 150-500 ms. A2, Line plots of error-related theta ICPS over time for Simon (gray) and SART (black). B2, As in A2, for alpha ICPS.

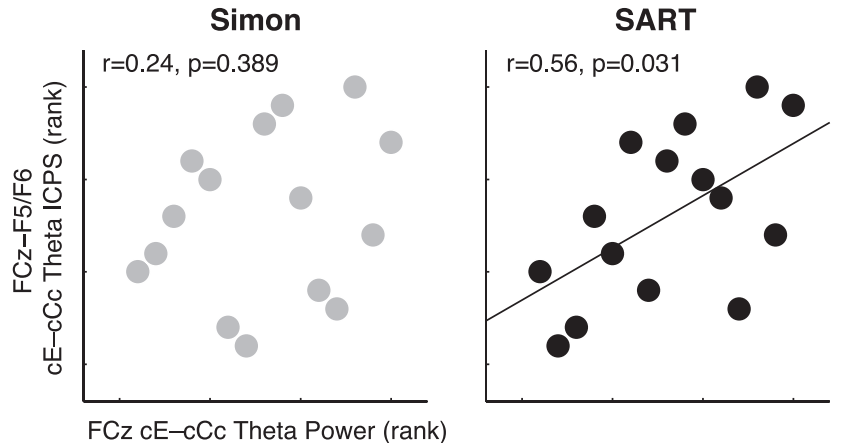

Figure 10. Cross-subject rank correlations between theta power and theta ICPS for the two tasks in Experiment 2. Error-related ( $\mathrm{CE}-\mathrm{cCC}$ ) interchannel theta phase synchronization between FCz and F5/6 correlates with error-related FCz theta power in the SART (right; black) but not in the Simon task (left; gray).

dow periresponse did not statistically confirm this $\left(F_{(1,14)}=2.6\right.$, $p=0.13)$.

In addition, we performed the same control analysis as described in Experiment 1, to test whether ICPS was driven by volume conduction. The circular V-test again indicated that the theta and alpha phase angle differences between channels of interest were different from zero and $\pi$.

\section{Cross-subject correlations}

Similar to our approach for Experiment 1, we looked whether the above EEG and behavioral dynamics would correlate across subjects. Consistent with the theta ICPS findings, the average time-frequency window of $50-300 \mathrm{~ms} \mathrm{FCz}$ theta power predicted FCz-F5/6 theta synchronization in the same time window only in the SART $\left(r_{(19)}=0.56, p=0.031\right)$ and not the Simon task $\left(r_{(19)}=0.24, p=0.39\right.$; Fig. 10). We did not find any statistical relationship between (post-)error RT and measures of power and synchrony.

\section{Discussion}

In this study we demonstrated that performance errors can result in different patterns of midfrontal theta-band $(4-8 \mathrm{~Hz})$ and posterior alpha-band $(8-12 \mathrm{~Hz})$ oscillatory activity. The degree and distribution of these EEG dynamics depended on the task and subtle manipulations to a task. Within the Simon task, when demands on sustained attention were lenient due to short blocks with intervening breaks, errors were driven by the irrelevant stimulus location and were followed primarily by increased midfrontal theta power, and increased theta synchronization between midfrontal sites $(\mathrm{FCz})$ and lateral prefrontal (F5/6) and posterior $(\mathrm{POz})$ sites. In contrast, in longer blocks in which response conflict was predictable, such that sustained attention could easily lapse, errors were not "impulsive," and elicited relatively less midfrontal theta and relatively more sustained parietooccipital alpha power. Moreover, this condition did not show an error-related increase in frontal theta synchronization, but rather an increase in right frontal-posterior alpha synchronization. The SART, also sensitive to attention lapses, did not show this longrange alpha network activity, but errors did elicit a robust and widely distributed posterior alpha suppression response, together with increased midfrontal theta power and prefrontal theta synchrony. This latter effect was even stronger than in the Simon task. These findings generally support the idea that there are at least two cortical mechanisms for performance monitoring during cognitive control and attention tasks (Cohen and van Gaal, 2012).

\section{Error-speeding and posterror slowing}

In conflict tasks, errors are thought to result from a failure to exert cognitive control over the motor system, such that a faster bottom-up processing of the irrelevant stimulus location determines the selected response (De Jong et al., 1994; Ridderinkhof, 2002). However, this may depend on the amount of experienced conflict, and the demands on sustained attention. In Experiment 1, the Sustained Attention condition showed less conflict, and while there was a clear capture at the fastest trials of the incon- 
gruent stimulus location in the General and Motor Control condition, this was not the case in the Sustained Attention condition. In Experiment 2, in contrast, the SART showed strong error speeding, which is consistent with previous literature (Mazaheri et al., 2009; O'Connell et al., 2009a). In a "dull" task such as the SART, subjects get into an automatic response mode, resulting in decreased reaction time, with lapses leading to fast errors (Robertson et al., 1997). In addition, all Simon conditions (Experiment 1 and 2) showed posterror slowing, which is thought to be a consequence of the recruitment of adaptation mechanisms to avoid future errors (Ridderinkhof et al., 2004a; Hester et al., 2007). The SART did not show this effect: because of the infrequent occurrence of NoGo trials, there may have been less need for posterror adaptation on the subsequent trial (Hester et al., 2007).

The above patterns of results show that behaviorally, errors within and across tasks can show differences in RT and accuracy dynamics, indicating that different types of errors may exist that relate to variations in required cognitive control on the one hand, and sustained attention on the other.

\section{Theta oscillations in a prefrontal network for performance monitoring and cognitive control}

On a neural level, the existence of different error types was revealed by differential involvement of frontal theta and posterior alpha activity after errors. Our study adds to a growing body of evidence that theta oscillations may be the putative "language" of a prefrontal network (Cohen, 2011) centered around the MFC, in which action monitoring and top-down control mechanisms functionally interact to optimize performance (Gehring and Knight, 2000; MacDonald et al., 2000; Botvinick et al., 2001). Similar to our findings, other work has shown that errors in conflict tasks are followed by increased MFC theta power (Luu et al., 2004; Trujillo and Allen, 2007; Womelsdorf et al., 2010), as well as higher MFC-DLPFC theta synchronization (Wang et al., 2005; Cavanagh et al., 2009, 2010), reflecting local coordinated activity as well as long-range orchestrated functional connectivity. Moreover, we were able to show that these processes are not unique to conflict tasks, but are also involved after errors in a task that primarily captures attentional failures. This finding is consistent with another study that showed frontal theta activity after errors in the SART (Mazaheri et al., 2009). Medial and lateral frontal theta dynamics have been brought forward as the underlying physiological source of the ERN (Luu and Tucker, 2001). Similar to previous studies that showed the ERN to fluctuate depending on task dynamics (Maier et al., 2008; O'Connell et al., 2009a), we here demonstrate that the degree and distribution of frontal theta activity shows similar task and instructiondependent sensitivity.

\section{Alpha oscillations in parieto-occipital and right frontoparietal networks of sustained attention}

Our general finding of a decrease in alpha power after errors is also in line with other studies (Carp and Compton, 2009; Mazaheri et al., 2009). It has been suggested that this change in alpha power reflects a refocusing of attention after a lapse (Macdonald et al., 2011). Similar to errors serving as signals to increase motor control to overcome conflict, errors due to lapses in sustained attention may serve as signals to increase task-related alertness on the next trial (Carp and Compton, 2009). We have found this "reorienting" alpha response to be more temporally sustained in a condition of the Simon task that was more vulnerable to lapses, compared with a condition that was more susceptible to location- driven conflict errors. Moreover, this effect was the most prevalent in the SART. In general, numerous studies have shown a relationship between decrease in alpha power and attentionrelated mechanisms, such as task-related alertness (Sadaghiani et al., 2010; Macdonald et al., 2011) and attentional demands (Ray and Cole, 1985). An increase in posterior alpha power has also been shown to predict errors in attention tasks before they occurred (O'Connell et al., 2009b; Bengson et al., 2012).

Moreover, in Experiment 1 we found increased posterror alpha synchronization between bilateral parieto-occipital sites and a right lateral prefrontal site in the Sustained Attention condition compared with the Motor Control condition. These alpha connectivity dynamics were less prominent in Experiment 2, although an earlier right-lateralized pattern could be recognized in the SART (data not shown). These observations fit previous literature. A right-lateralized frontoparietal network has been proposed to play a role in exerting top-down attentional control over lower sensory regions as a reorienting response (Corbetta and Shulman, 2002), which can be triggered by lapses in sustained attention (Weissman et al., 2006). Patients with right frontal lesions have been shown to exhibit sustained attention deficits (Rueckert and Grafman, 1996; Shallice et al., 2008). In addition to findings of anticipatory top-down modulation of sensory processing, reflected by right prefrontal modulation of parietooccipital alpha activity (Capotosto et al., 2009; Zanto et al., 2010, 2011), we here thus suggest that a similar alpha network may be recruited after lapse-related errors, as a top-down refocusing of sustained attention.

\section{Limitations}

In contrast to clear and robust power effects in response to errors, some of our interchannel phase synchrony results were contrary to our predictions: most notably the absence of error-related theta synchrony in the Simon task of Experiment 2, and less clear right frontoparietal alpha connectivity in the SART. It is possible that these discrepancies were related to a relatively small number of trials per subject.

A second limitation is that the differences between the EEG signatures of errors in the different conditions/tasks were more quantitative than qualitative. Arguably, in most (if not all) conflict and attention tasks, errors result from temporary "failures" of different (and possibly qualitatively distinct) neurocognitive processes. In the present study, we tried to shift the balance of error-mechanisms by means of subtle manipulations and different tasks, but it is likely that both motor control failures and attention lapses contributed to errors in all conditions and tasks. Along similar lines, it is likely that other mechanisms can lead to errors, whereas we focused only on two.

Ideally, one could classify each error as being driven by conflict or attention lapse. Future studies using single-trial principle component analysis or classification-based techniques might better separate contributions of different error-processing mechanisms on a trial-to-trial basis. Such an approach might also better elucidate the relationship between these different mechanisms and behavioral posterror adaptation.

\section{Conclusions}

In this study, we aimed to characterize the involvement of different brain networks in response to errors. Overall, both theta and alpha frequency bands contributed to posterror EEG activity. By shifting the balance between two error types that we hypothesized to be present throughout a typical conflict task, and by directly comparing such a conflict task with a sustained attention task, we 
showed that not all errors are alike: different types of errors may coexist, each recruiting their own mixture of posterror electrophysiological processes. When investigating performance errors, one should consider what types of errors are being produced, and what patterns of neural activity might result.

\section{References}

Alexander WH, Brown JW (2011) Medial prefrontal cortex as an actionoutcome predictor. Nat Neurosci 14:1338-1344. CrossRef Medline

Bengson JJ, Mangun GR, Mazaheri A (2012) The neural markers of an imminent failure of response inhibition. Neuroimage 59:1534-1539. CrossRef Medline

Berens P (2009) CircStat: A MATLAB toolbox for circular statistics. J Stat Softw 31:1-21.

Botvinick MM, Braver TS, Barch DM, Carter CS, Cohen JD (2001) Conflict monitoring and cognitive control. Psychol Rev 108:624-652. CrossRef Medline

Burle B, van den Wildenberg WPM, Ridderinkhof KR (2005) Dynamics of facilitation and interference in cue-priming and Simon tasks. Eur J Cogn Psychol 17:619-641. CrossRef

Capotosto P, Babiloni C, Romani GL, Corbetta M (2009) Frontoparietal cortex controls spatial attention through modulation of anticipatory alpha rhythms. J Neurosci 29:5863-5872. CrossRef Medline

Carp J, Compton RJ (2009) Alpha power is influenced by performance errors. Psychophysiology 46:336-343. CrossRef Medline

Carter CS, Braver TS, Barch DM, Botvinick MM, Noll D, Cohen JD (1998) Anterior cingulate cortex, error detection, and the online monitoring of performance. Science 280:747-749. CrossRef Medline

Cavanagh JF, Cohen MX, Allen JJ (2009) Prelude to and resolution of an error: EEG phase synchrony reveals cognitive control dynamics during action monitoring. J Neurosci 29:98-105. CrossRef Medline

Cavanagh JF, Frank MJ, Klein TJ, Allen JJ (2010) Frontal theta links prediction errors to behavioral adaptation in reinforcement learning. Neuroimage 49:3198-3209. CrossRef Medline

Christ S, Falkenstein M, Heuer H, Hohnsbein J (2000) Different error types and error processing in spatial stimulus-response-compatibility tasks: behavioural and electrophysiological data. Biol Psychol 51:129-150. CrossRef Medline

Cohen MR, Maunsell JH (2011) When attention wanders: how uncontrolled fluctuations in attention affect performance. J Neurosci 31:1580215806. CrossRef Medline

Cohen MX (2011) Error-related medial frontal theta activity predicts cingulate-related structural connectivity. Neuroimage 55:1373-1383. CrossRef Medline

Cohen MX, Cavanagh JF (2011) Single-trial regression elucidates the role of prefrontal theta oscillations in response conflict. Front Psychol 2:30. Medline

Cohen MX, van Gaal S (2012) Dynamic interactions between large-scale brain networks predict behavioral adaptation after perceptual errors. Cereb Cortex. Advance online publication. Retrieved April 18, 2012. doi: 10.1093/cercor/bhs069. CrossRef Medline

Cohen MX, Ridderinkhof KR, Haupt S, Elger CE, Fell J (2008) Medial frontal cortex and response conflict: Evidence from human intracranial EEG and medial frontal cortex lesion. Brain Res 1238:127-142. CrossRef Medline

Cohen MX, van Gaal S, Ridderinkhof KR, Lamme VA (2009) Unconscious errors enhance prefrontal-occipital oscillatory synchrony. Front Hum Neurosci 3:54. Medline

Corbetta M, Shulman GL (2002) Control of goal-directed and stimulusdriven attention in the brain. Nat Rev Neurosci 3:201-215. Medline

De Jong R, Liang CC, Lauber E (1994) Conditional and unconditional automaticity: a dual-process model of effects of spatial stimulus-response correspondence. J Exp Psychol Hum Percept Perform 20:731-750. CrossRef Medline

Delorme A, Makeig S (2004) EEGLAB: an open source toolbox for analysis of single-trial EEG dynamics including independent component analysis. J Neurosci Methods 134:9-21. CrossRef Medline

Dockree PM, Kelly SP, Foxe JJ, Reilly RB, Robertson IH (2007) Optimal sustained attention is linked to the spectral content of background EEG activity: greater ongoing tonic alpha $(\sim 10 \mathrm{~Hz})$ power supports successful phasic goal activation. Eur J Neurosci 25:900-907. CrossRef Medline
Egner T (2007) Congruency sequence effects and cognitive control. Cogn Affect Behav Neurosci 7:380-390. CrossRef Medline

Fisher NI (1996) Statistical analysis of circular data. Cambridge: UP.

Gehring WJ, Knight RT (2000) Prefrontal-cingulate interactions in action monitoring. Nat Neurosci 3:516-520. CrossRef Medline

Gehring WJ, Goss B, Coles MGH, Meyer DE, Donchin E (1993) A neural system for error detection and compensation. Psychol Sci 4:385-390. CrossRef

Gratton G, Coles MG, Donchin E (1992) Optimizing the use of information: strategic control of activation of responses. J Exp Psychol Gen 121: 480-506. CrossRef Medline

Ham TE, de Boissezon X, Leff A, Beckmann C, Hughes E, Kinnunen KM, Leech R, Sharp DJ (2012) Distinct frontal networks are involved in adapting to internally and externally signaled errors. Cereb Cortex. Advance online publication. Retrieved March 16, 2012. doi: 10.1093/cercor/bhs056. CrossRef Medline

Hanslmayr S, Pastötter B, Bäuml KH, Gruber S, Wimber M, Klimesch W (2008) The electrophysiological dynamics of interference during the Stroop task. J Cogn Neurosci 20:215-225. Medline

Hester R, Barre N, Mattingley JB, Foxe JJ, Garavan H (2007) Avoiding another mistake: error and posterror neural activity associated with adaptive posterror behavior change. Cogn Affect Behav Neurosci 7:317-326. CrossRef Medline

Kayser J, Tenke CE (2006) Principal components analysis of Laplacian waveforms as a generic method for identifying ERP generator patterns: I. Evaluation with auditory oddball tasks. Clin Neurophysiol 117:348-368. CrossRef Medline

Kerns JG, Cohen JD, MacDonald AW 3rd, Cho RY, Stenger VA, Carter CS (2004) Anterior cingulate conflict monitoring and adjustments in control. Science 303:1023-1026. CrossRef Medline

Lachaux JP, Rodriguez E, Martinerie J, Varela FJ (1999) Measuring phase synchrony in brain signals. Hum Brain Mapp 8:194-208. CrossRef Medline

Leuthold H (2011) The Simon effect in cognitive electrophysiology: a short review. Acta Psychol 136:203-211. CrossRef

Luu P, Tucker DM (2001) Regulating action: alternating activation of midline frontal and motor cortical networks. Clin Neurophysiol 112:12951306. CrossRef Medline

Luu P, Tucker DM, Makeig S (2004) Frontal midline theta and the errorrelated negativity: neurophysiological mechanisms of action regulation. Clin Neurophysiol 115:1821-1835. CrossRef Medline

MacDonald AW 3rd, Cohen JD, Stenger VA, Carter CS (2000) Dissociating the role of the dorsolateral prefrontal cortex and anterior cingulate cortex in cognitive control. Science 288:1835-1838. CrossRef Medline

Macdonald JS, Mathan S, Yeung N (2011) Trial-by-trial variations in subjective attentional state are reflected in ongoing prestimulus EEG alpha oscillations. Front Psychol 2:82. Medline

Maier M, Steinhauser M, Hübner R (2008) Is the error-related negativity amplitude related to error detectability? Evidence from effects of different error types. J Cogn Neurosci 20:2263-2273. CrossRef Medline

Manuel AL, Bernasconi F, Murray MM, Spierer L (2012) Spatio-temporal brain dynamics mediating post-error behavioral adjustments. J Cogn Neurosci 24:1331-1343. CrossRef Medline

Mazaheri A, Nieuwenhuis IL, van Dijk H, Jensen O (2009) Prestimulus alpha and mu activity predicts failure to inhibit motor responses. Hum Brain Mapp 30:1791-1800. CrossRef Medline

Nigbur R, Cohen MX, Ridderinkhof KR, Stürmer B (2012) Theta dynamics reveal domain-specific control over stimulus and response conflict. J Cogn Neurosci 24:1264-1274. CrossRef Medline

Nunez PL, Srinivasan R, Westdorp AF, Wijesinghe RS, Tucker DM, Silberstein RB, Cadusch PJ (1997) EEG coherency I: statistics, reference electrode, volume conduction, Laplacians, cortical imaging, and interpretation at multiple scales. Electroencephalogr Clin Neurophysiol 103:499-515. Medline

O'Connell RG, Dockree PM, Bellgrove MA, Turin A, Ward S, Foxe JJ, Robertson IH (2009a) Two types of action error: electrophysiological evidence for separable inhibitory and sustained attention neural mechanisms producing error on go/no-go tasks. J Cogn Neurosci 21:93-104. CrossRef Medline

O'Connell RG, Dockree PM, Robertson IH, Bellgrove MA, Foxe JJ, Kelly SP (2009b) Uncovering the neural signature of lapsing attention: electrophysiological signals predict errors up to $20 \mathrm{~s}$ before they occur. J Neurosci 29:8604-8611. CrossRef Medline

Ray WJ, Cole HW (1985) EEG alpha activity reflects attentional demands, 
and beta activity reflects emotional and cognitive processes. Science 228: 750-752. CrossRef Medline

Ridderinkhof KR (2002) Micro- and macro-adjustments of task set: activation and suppression in conflict tasks. Psychol Res 66:312-323. CrossRef Medline

Ridderinkhof KR, Ullsperger M, Crone EA, Nieuwenhuis S (2004a) The role of the medial frontal cortex in cognitive control. Science 306:443-447. CrossRef Medline

Ridderinkhof KR, van den Wildenberg WP, Segalowitz SJ, Carter CS (2004b) Neurocognitive mechanisms of cognitive control: the role of prefrontal cortex in action selection, response inhibition, performance monitoring, and reward-based learning. Brain Cogn 56:129-140. CrossRef Medline

Robertson IH, Manly T, Andrade J, Baddeley BT, Yiend J (1997) “Oops!”: Performance correlates of everyday attentional failures in traumatic brain injured and normal subjects. Neuropsychologia 35:747-758. CrossRef Medline

Rueckert L, Grafman J (1996) Sustained attention deficits in patients with right frontal lesions. Neuropsychologia 34:953-963. CrossRef Medline

Sadaghiani S, Scheeringa R, Lehongre K, Morillon B, Giraud AL, Kleinschmidt A (2010) Intrinsic connectivity networks, alpha oscillations, and tonic alertness: a simultaneous electroencephalography/functional magnetic resonance imaging study. J Neurosci 30:10243-10250. CrossRef Medline

Shallice T, Stuss DT, Alexander MP, Picton TW, Derkzen D (2008) The multiple dimensions of sustained attention. Cortex 44:794-805. CrossRef Medline

Simon JR, Rudell AP (1967) Auditory S-R compatibility: the effect of an irrelevant cue on information processing. J Appl Psychol 51:300-304. CrossRef Medline

Smallwood J, Schooler JW (2006) The restless mind. Psychol Bull 132:946958. CrossRef Medline

Srinivasan R, Winter WR, Ding J, Nunez PL (2007) EEG and MEG coherence: measures of functional connectivity at distinct spatial scales of neocortical dynamics. J Neurosci Methods 166:41-52. CrossRef Medline
Stam CJ, Nolte G, Daffertshofer A (2007) Phase lag index: assessment of functional connectivity from multi channel EEG and MEG with diminished bias from common sources. Hum Brain Mapp 28:1178-1193. CrossRef Medline

Steinhauser M, Kiesel A (2011) Performance monitoring and the causal attribution of errors. Cogn Affect Behav Neurosci 11:309-320. CrossRef Medline

Trujillo LT, Allen JJ (2007) Theta EEG dynamics of the error-related negativity. Clin Neurophysiol 118:645-668. CrossRef Medline

van den Wildenberg WP, Wylie SA, Forstmann BU, Burle B, Hasbroucq T, Ridderinkhof KR (2010) To head or to heed? Beyond the surface of selective action inhibition: a review. Front Hum Neurosci 4:222. Medline

Vanni S, Revonsuo A, Hari R (1997) Modulation of the parieto-occipital alpha rhythm during object detection. J Neurosci 17:7141-7147. Medline

Wang C, Ulbert I, Schomer DL, Marinkovic K, Halgren E (2005) Responses of human anterior cingulate cortex microdomains to error detection, conflict monitoring, stimulus-response mapping, familiarity, and orienting. J Neurosci 25:604-613. CrossRef Medline

Weissman DH, Roberts KC, Visscher KM, Woldorff MG (2006) The neural bases of momentary lapses in attention. Nat Neurosci 9:971-978. CrossRef Medline

Winter WR, Nunez PL, Ding J, Srinivasan R (2007) Comparison of the effect of volume conduction on EEG coherence with the effect of field spread on MEG coherence. Stat Med 26:3946-3957. CrossRef Medline

Womelsdorf T, Johnston K, Vinck M, Everling S (2010) Theta-activity in anterior cingulate cortex predicts task rules and their adjustments following errors. Proc Natl Acad Sci U S A 107:5248-5253. CrossRef Medline

Zanto TP, Rubens MT, Bollinger J, Gazzaley A (2010) Top-down modulation of visual feature processing: the role of the inferior frontal junction. Neuroimage 53:736-745. CrossRef Medline

Zanto TP, Rubens MT, Thangavel A, Gazzaley A (2011) Causal role of the prefrontal cortex in top-down modulation of visual processing and working memory. Nat Neurosci 14:656-661. CrossRef Medline 